\title{
Paisagem infinita: do engenho de açúcar aos bens culturais
}

\author{
Infinite landscape: from sugar engine to cultural goods
}

Paisaje infinito: del ingenio azucarero a los bienes culturales

Saulo di Tarso Begliomini de Araújo ${ }^{1}$

\section{Resumo}

ARAÚJO, S. di. T. B. de. Paisagem infinita: do engenho de açúcar aos bens culturais. Rev. CéTrópico, v. 44, n. 1, p. 11-35, 2020. DOI: https://doi.org/10.33148/cetropicov44n1(2020)art1

O presente artigo investiga a formação de uma nova paisagem cultural que emerge com o declínio da economia cafeeira e a ascensão da cana-de-açúcar no nordeste do estado de São Paulo, refletindo sobre as relações entre a paisagem cultural pernambucana e paulista. A pesquisa tem como foco e objeto de estudo o Engenho Central, inaugurado em 1906 na região de Ribeirão Preto, hoje, Museu da Cana. Traçando um panorama histórico, artístico e cultural do Brasil, busca-se compreender as transformações e os novos valores culturais que surgem desse processo, evidenciando o entrelaçamento entre arte e pioneirismo econômico. A história da criação do Museu da Cana cruzou os caminhos dos maiores pioneiros modernos brasileiros em matéria de arte e cultura, como Aloisio Magalhães, Acácio e Janete Borsoi, Clarival do Prado Valadares, Cicero Dias, Burle Marx, Alexandre Wollner. Por fim, o artigo analisa o papel e a importância estratégica da economia empresarial aliada à arte, design e os museus, da memória, da economia da cultura, do capital cultural e dos bens culturais para a emancipação social, científico-tecnológica, econômica, bem como para um desenvolvimento autônomo do país.

Palavras-chave: Paisagem cultural. Museu da Cana. Memória. Bens culturais. Economia da cultura. Design e arte brasileira.

\section{Abstract}

ARAÚJO, S. di. T. B. de Infinite landscape: from sugar engine to cultural goods. Rev. C\&Trópico, v. 44, n. 1, p. 11-35, 2020. DOI: https://doi.org/10.33148/cetropicov44n1(2020)art1

This article investigates the formation of a new cultural landscape that emerged with the decline of the coffee economy and the rise of the sugar cane industry in the northeast of the state of São Paulo. It reflects on the relationships between the cultural landscapes of the states of Pernambuco and São Paulo. The research focuses on the "Engenho Central" (Central Mill) inaugurated in 1906 near Ribeirão Preto, São Paulo and has since become the Sugarcane Museum ("Museu

Artista visual e curador. Em 2018 fundou a Tangram Museologia. Atualmente é ligado à Sociedade Brasileira para o Progresso da Ciência (SBPC) e ao Conselho Internacional de Museus (ICOM Brasil). E-mail: saulo@ criptext.com. Orcid: https://orcid.org/0000-0002-5316-2412 
da Cana"). My intent is to facilitate the understanding of transformations and new cultural values by tracing a historical, artistic and cultural panorama of Brazil demonstrating the interweaving of art and the pioneering spirit of the time. The paths of many of the greatest modern Brazilian pioneers in the field of art and culture crossed in the course of the creation of the Museu da Cana. Names include; Aloísio Magalhães, Acácio and Janete Borsoi, Clarival do Prado Valadares, Cícero Dias, Burle Marx and Alexandre Wollner. Lastly, the article analyzes the role and strategic importance of the business economy in league with art, design and the museums, cultural economics, cultural capital and cultural assets for social, scientific-technological, economic emancipation, as well as for the autonomous development of the country.

Keywords: Cultural landscape. Cana Museum. Memory. Cultural goods. Culture economics. Brazilian design and art.

\section{Resumen}

ARAÚJO, S. di. T. B. de. Paisaje infinito: del ingenio azucarero a los bienes culturales. Rev. CひTrópico, v. 44, n. 1, p. 11-35, 2020. DOI:https://doi.org/10.33148/cetropicov44n1(2020) art1

Este artículo investiga la formación de un nuevo paisaje cultural que surge con el declive de la economía cafetera y el aumento de la caña de azúcar en el noreste del estado de São Paulo, reflexionando sobre las relaciones entre el paisaje cultural de Pernambuco y São Paulo. La investigación tiene como foco y objeto de estudio el Engenho Central, inaugurado en 1906 en la región de Ribeirão Preto, hoy, Museu da Cana. Rastreando un panorama histórico, artístico y cultural de Brasil, buscamos comprender las transformaciones y los nuevos valores culturales que surgen de este proceso, mostrando el entrelazamiento entre el arte y el pionero económico. La historia de la creación del Museu da Cana se cruzó en el camino de los grandes pioneros brasileños modernos en el campo del arte y la cultura, como Aloisio Magalhães, Acácio y Janete Borsoi, Clarival do Prado Valadares, Cicero Dias, Burle Marx, Alexandre Wollner. Finalmente, el artículo analiza el papel y la importancia estratégica de la economía empresarial combinada con el arte, el diseño y los museos, la memoria, la economía de la cultura, el capital cultural y los activos culturales para la emancipación económica social, científica y tecnológica, así como para el desarrollo autónomo del país.

Palabras clave: Paisaje cultural. Museo de Cana. Memoria. Bienes culturales. Economía de la cultura. Diseño y arte brasileño.

Data de submissão: 02/05/2020

Data de aceite: 08/06/2020 


\section{Introdução}

O Engenho Central foi uma tipo de viveiro de empresários, onde se proliferou muita energia positiva. Foi um lugar muito saudável; muitas iniciativas nasceram ou se inspiraram no Engenho. Algo muito positivo. "Na época da Zanini (1970) pensei em outro museu, da história do açúcar, mas moderno, em outro local, que seria em Sertãozinho. Tive contato sobre a ideia com o arquiteto Borsoi, de Recife, Pernambuco, mas não prosperou (BIAGIL, 2003)".

[...] No processo de evolução de uma cultura, nada existe propriamente de 'novo'. O 'novo' é apenas uma forma transformada do passado, enriquecida na continuidade do processo, ou novamente revelada, de um repertório latente. $\mathrm{Na}$ verdade, os elementos são sempre os mesmos: apenas a visão pode ser enriquecida, por novas incidências de luz, nas diversas faces do mesmo cristal. (MAGALHÃES; LEITE, 2017, p. 258)

[...] A política paternalista de dizer que o artesanato deve permanecer como tal é uma política errada; culturalmente é impositiva porque somos nós, de um nível cultural, que apreciamos aquele objeto pelas suas características, gostaríamos que ele ficasse ali. Então, é uma coisa insuportável, errada e de certo modo totalitária, você impor a uma coletividade, a um grupo, que permaneça naquele ponto. $\mathrm{O}$ remédio, a coisa que se oferece, é a ideia de que ele repita mais. Que passe a ter mais benefício através da repetição reiterada e monótona daquele momento da trajetória. E isso é inadequado porque você corta o fio da trajetória, o fio da invenção, da evolução da invenção, para que ele permaneça parado no tempo. O caminho, a meu ver, não é esse; o caminho é identificar isso, ver o nível de complexidade em que está, qual é o desenho do próximo passo e dar o estímulo para que ele dê esse passo. (MAGALHÃES; LEITE, 2017)

Só através das artes as civilizações sobrevivem. São elas, e somente elas, que escrevem a vida de um povo, de um homem (DIAS, 2011).

\section{Revolução das artes}

A coluna infinita de Constantin Brancusi é uma revolução. Não só no sentido da Arte Moderna, mas como corolário de uma fase humana que se torna futura e originária ao mesmo tempo. É uma rocha que atinge o alto sem nenhum flerte com 
a investigação de materiais modernos para escultura e, assim, contempla a silenciosa história da arte da escultura.

Pode-se dizer que a obra representa a história da linguagem da escultura em diversas dimensões do espaço e do tempo e da linguagem escultórica. Nova e antiga, ela revoluciona a modernidade da escultura moderna sem nenhum traço de renovação técnica com relação à era da escultura clássica. Simplesmente, Coluna Infinita avança para o alto, de modo incomum a relação peso-equilíbrio, qualidade que define, por excelência, a linguagem da escultura. Um patrimônio material e altamente imaterial, ao mesmo tempo, resgatando os séculos anteriores da arte de esculpir, torna-se moderno apenas por avançar o limite da escultura clássica para a modernidade, diferindo a plástica da emoção, por exemplo, de Rodin e toda a emoção representativa. Diferente, Constantin Brancusi vai no cerne da afetividade humana e a sintetiza de todos os rebuscamentos.

Figura 1: A coluna infinita de Brancusi.

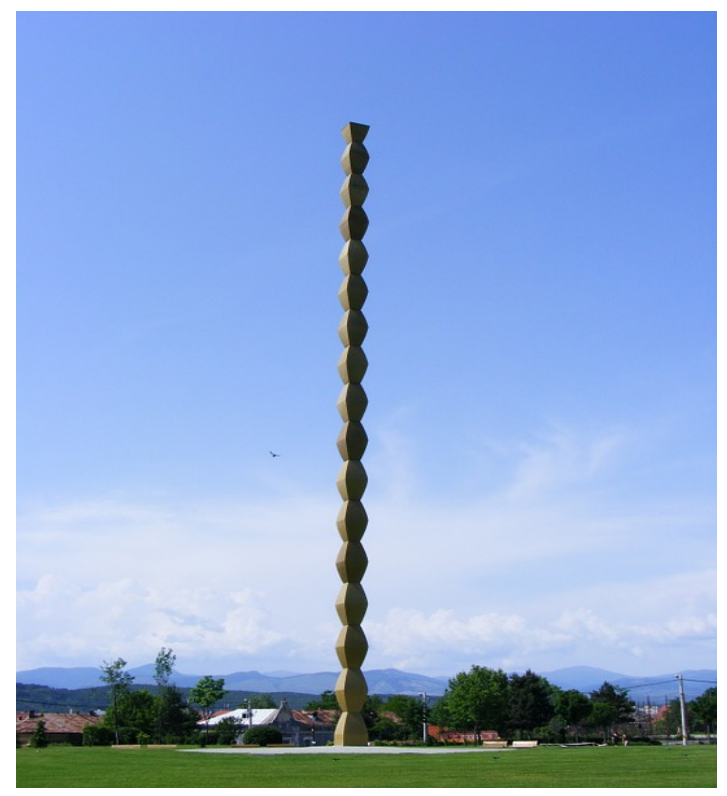

Fonte: Autor desconhecido ${ }^{2}$.

Nesta complexidade, encontra-se a escultura da escultura. Vê-se com clareza que o modo como o escultor trabalhou, ao mesmo tempo, representa toda a história do trabalho dos escultores no Ocidente. Representa, além da escultura, a história do esculpir. Dos cânones a minimização da linguagem da escultura ao mínimo da linguagem escultórica. Brancusi é para a escultura moderna o que a Arte Concreta é para a

2 Disponível em: https://pixabay.com/pt/photos/coluna-escultura-brancusi-sem-fim-87553/. 
pintura que chegou mais tarde no Minimalismo. Curiosa escala, remete à simplicidade e ao vazio da passagem bíblica que narra o sopro divino no corpo de barro do homem esculpido por Deus. Brancusi não é o autor do David de Michelangelo, tampouco Rodin, autor de Burgueses de Calais. Não é um anônimo escultor de pirâmides egípcias, monumentos incas e entidade líticas misteriosas como os corpos da Ilha de Páscoa ou monumentos abissais como Partenon e Stonehenge. Mas é em sua grandeza escalar a límpida tradução dos sentimentos humanos mais afinados à essência humana. A linguagem de Brancusi é dotada da qualidade de vanguarda que cria as obras singulares de um tempo e que, no caso da Coluna Infinita, traz um mistério revelado pela paisagem constante que se vê em torno da obra, como parte da obra escultórica. Céu, terra e ar. Rocha esculpida para o alto e do chão para seu limite extremo em altura, desafia as leis do equilíbrio e aponta o céu sendo tocada pelo ar em movimento, a constância das massas de ar que criam a tradução constante da paisagem, em torno de sua grandeza escalar, revelando o cosmos que se guarda na paisagem terrena, que se traduz no vento que venta em torno de sua obra estática no meio da paisagem.

A Coluna Infinita, portanto, se traduz pelo silêncio do espaço e o enaltecimento do tempo se observada desta forma. O tempo e todo o seu movimento, visto através da escultura, passam a pertencer ao corpo da obra. O espaço emudece na simplicidade de triangulações para o alto. Não é um apelo sensorial como a massa ruidosa de um Antoine Bourdelle, ou sentimentos finos e sensuais que tangem a espiritualidade de um Bernini. Tudo no espaço é silêncio. Silêncio material e simbólico, criando a atmosfera através da qual o tempo grita o silêncio em torno da Coluna Infinita.

Assim, Brancusi, ao exaltar a matéria escultórica pelo mínimo, torna máxima a escala do tempo na linguagem da escultura. Torna o tempo mais importante, na estética do século XX, do que a própria música moderna o fará em dois séculos. Pode-se até dizer que o silêncio da matéria de Brancusi expõe valores etéreos de modo estrondoso e minimiza o silêncio da forma radicalmente, como fará o músico norte-americano, John Cage, mais tarde na peça 4,33. Mas há uma diferença inversamente proporcional entre as duas obras: a música em silêncio de Cage é para ser ouvida em silêncio nas salas de concerto, ao passo que, a Coluna Infinita de Brancusi jamais poderia ser vista dentro do interior de um museu que não fosse a céu aberto. Logo, ela é a consagração de um lugar, uma paisagem, ao mesmo tempo que um ponto de mutação da linguagem da escultura. Diferente de um monumento pensado para o espaço ao redor, como a célebre Fontana di Trevi, a Coluna Infinita se serve da paisagem e a coloca no mesmo silêncio definitivo que a pintura moderna a colocou.

Lembramos assim que a arte imita a vida e que a vida pode imitar a arte nas suas diversas dimensões. Em torno da escultura a vida percorre.

Simbolicamente, como a altitude de Brancusi, na coluna infinita, existem arranha-céus. E assim como arranha-céus, existem as chaminés, para que escapassem os vapores da Revolução Industrial. Uma vez silenciadas pelo fim da produção que as alimenta, por vezes passam a ser consideradas monumentos. 
Assim como as chaminés e esculturas que resultam do trabalho humano, todo ser humano é potencialmente escultor, já que o corpo humano se traduz da escultura na sua sacralidade Ocidental. Corpo cuja ação do pensamento modela a paisagem.

Vista desse modo, a escultura não é apenas uma linguagem da arte, mas uma arte que, a todo momento, simboliza a gênese humana e a capacidade humana de traduzir o humano ao esculpir o mundo. Logo, a escultura é um ato de vida, o que torna a ideia da escultura semelhante à noção do trabalho, das relações, da forma como a intensão humana cria sua realidade no mundo e das diversas formas do trabalho humano, fatores diversos e multiplicados da vida. Além disso, as diversas formas do trabalho humano são fatores diversos e multiplicados da vida. Sem dúvida é na arte, na filosofia, na religiosidade, na ciência e na tecnologia que se encontram as formas mais elevadas do trabalho e da dedicação da vida humana à sua existência. Ocorre que não há humanidade e nem elevação sem o conjunto da humanidade. Ou seja, indivíduo e coletividade são um. Da coletividade se nasce e para a coletividade social se retorna.

A natureza de um expoente humano é sempre resultante de uma imensa coletividade, de linhagens e percepções múltiplas que décadas a mais ou a menos se polarizam da percepção de sujeitos dotados da força de sintetizar a vida humana através da arte, da ciência, da cultura, da noção primordial da sociedade que traduz o modo de vida desde a religiosidade até as formas mais sofisticadas da economia e das redes de comunicação.

Surge assim, da aglomeração humana, o indivíduo que se destaca por razões até hoje desconhecidas. Exemplos, no Brasil, como Manoel de Barros, Gilberto Freire, Cícero Dias, Mário Pedrosa, Alfredo Volpi, Candido Portinari, Pelé, Mário Schenberg e a interminável lista célebre, dentre os quais, Celso Furtado, Mario de Andrade, Álvaro Vieira Pinto, Capanema, Rangel Pestana e tantos outros que nunca tendo se tornado célebres foram igualmente grandes humanistas.

Das raízes de um povo diverso e anônimo, remonta a história dos Engenhos no Brasil. Com ela, a história do Novo Mundo e da distribuição do açúcar pelos quatro cantos do mundo, ninguém jamais saberá quantos corpos foram alimentados pelos dons da nossa terra. Fundados em Pernambuco e São Vicente, os primeiros engenhos do Brasil jamais deixaram de ser a rota de entrada de tantos povos que ergueram a nação desde tempos primordiais até a porta da era Global. Passadas as tentativas malsucedidas de escravizarem-se os indígenas e o período da escravidão, o Brasil encontra a modernidade e com as contradições do subdesenvolvimento que ainda persiste em nosso modelo político. A mitologia do Brasil Moderno é repleta de pioneiros que, sem sucessão, acabam com as ideias e ações soterradas depois de sua morte. Entre fios e fios de gente que tecem a história, assim, acaba por se perder o tecido da vida, a não ser pela força daqueles que, imbuídos da própria consciência, lutam pela memória de seus antepassados e pela escala de valores por eles erigida. Riqueza no Brasil, por este motivo, sempre anda em alto contraste com a miséria humana. No legado sucessivo de séculos de 
exploração, a história cai enquanto as fortunas se fazem e trocam de mãos ao mesmo tempo que as nações do Velho Mundo que nos colonizaram detêm as maiores riquezas que daqui foram suprimidas contendo registros históricos mais apurados que os nossos próprios, existentes em instituições que são pequenas para abarcar a nossa grandeza, ou que padecem de recursos para manterem a sua vocação, exemplos como a Biblioteca Nacional, o Museu Nacional recém incendiado, ou mesmo a miríade de museus que surgem sem sair do lugar.

E a pergunta fundamental que devemos nos fazer hoje é: entre tantos célebres, quem são os anônimos que perfazem as histórias das fortunas e da existência humana em máximo grau? E, continuando: quem são estes poetas que, como Manoel de Barros, identificam o artista nascendo da ontologia da decadência social? Quem são estas figuras como a doceira e genial poetisa Cora Coralina? O que trazem os corpos para a matéria da nossa máxima capacidade e multiplicação das capacidades humanas? Quem somos nós e quem nós queremos ser entre variadas eras do Capital, em tempos de capital humano, capital cultural e bens culturais? Vamos reproduzir a República de Platão, sem poetas, e, no entanto, erigindo a beleza grega de modo contínuo a partir de calabouços de escuridão que servem como base subterrânea de monumentos expostos de beleza? Qual é a sociedade que queremos em si e entre semelhantes? Será a utopia de bem-estar uma utopia em tempos que a tecnologia faculta a velocidade de criação, multiplicação e distribuição das riquezas? Qual é o papel do capital cultural e da memória entre gerações, onde entram os museus, as instituições, as grandes empresas, as nações? Quais fronteiras precisam ser eliminadas, além das geográficas, para que os degraus se planifiquem entre o topo e a base da existência humana? Quando de fato nascerá a Engenharia social neste nível de eficácia?

Já era hora de rompermos os limites da Casa Grande e Senzala não apenas na realidade real, mas também na nossa imaginação. Aliás a Imigração no Brasil estilhaçou as mitologias de Casa Grande e Senzala. O modo de trabalho trazido pelos imigrantes faz essa transformação definitivamente, ainda que persista o modelo arcaico de trabalho no Brasil que não se livrará da injustiça e terá dentro dos canaviais a histórica greve de Guariba. Em tempo, as revoluções culturais das décadas de 1920 e 30 já nos demonstram que, embora brilhantes como mentalidade, somos altamente falíveis como ação social. O Brasil é um país onde somos dotados da capacidade de construir e igualmente da capacidade de destruir. E se destrói com eficácia, pela negação, pelo abandono, pelo esquecimento, pela diferença de gerações ou pelos métodos propositais. É raro o fenômeno onde ocorre o oposto: afirmação, autonomia, memória consciente, diálogo sucessivo entre geração. No entanto, as gerações de imigrantes, politizadas e dotadas do senso de justiça material, mudam as relações de trabalho no Brasil. Aos poucos, nomes pioneiros vão surgindo em toda paisagem social brasileira do século XX.

$\mathrm{Na}$ Modernidade, o Brasil esboçou rápidas mudanças que, no entanto, não foram suficientemente fortes para concluir a verdadeira transição do Brasil para a Modernidade. A Semana de 22 é um fruto artístico nitidamente oriundo 
da sociedade cafeeira. Antes deles, o apogeu de Pernambuco na história cultural brasileira é inegável. Num dos lugares mais ricos do mundo, foi o açúcar que financiou a memória cultural brasileira e seu grande legado nos primeiros séculos. De Joaquim Nabuco a Aloísio Magalhães, a herança cultural é indiscutível. Esta narrativa só começa a mudar quando o engenheiro Euclides da Cunha escreve os Sertões, Mário de Andrade cria a Missão e as pontes do mapa cultural brasileiro começam a materializar seus cruzamentos. E como tal, a modernidade do passado está fadada, na contemporaneidade, a cruzar os seus eixos. Rio e São Paulo antes de se tornarem capitais eram sertões da costa atlântica entrecortadas pelo cerrado em suas fronteiras. Com relação a Pernambuco, em nada se compara ao legado de séculos interagindo a cultura e a arte populares a chamada arte e cultura clássicas, feita por sujeitos eruditos. Quando a Escravidão termina, o estado de Pernambuco entra em festa. Desta festa sem fim de onde vem os Maracatus. O Rio é a capital da Monarquia e São Paulo nem mesmo capital irá se tornar a não ser da economia. Em moldes bem mais diretos é a capital do fluxo estrangeiro moderno tanto quanto o Rio de Janeiro foi a terra tropical daqueles que almejavam ser livres das amarras do velho mundo. Sem mais, sem esquecer Aurélio Buarque de Holanda que em seu dicionário edificou um Brasil de múltiplos mares que pensa em diversas línguas, mas fala português. A influência hispânica inegavelmente galega do interior de Pernambuco traz um fenômeno pouco estudado para nós: galegos de origem que continuaram pensando e entonando a língua galega que falam em português. Xeixos de pedra. Pedras de açúcar dissolvidas em cal. E foi este Brasil do futuro, como mencionou Stefan Zweig, uma pátria permitida pela economia do açúcar. E por séculos, o apogeu pernambucano foi mantido e mantendo-se até quando a decadência deste ciclo inicia na década de 1930 como narra o pintor pernambucano Cícero Dias:

Como as árvores e suas raízes, a natureza tinha seu tempo. Matemática divina que só Deus conta na vida do homem. As meninas, já moças, e os meninos, já rapazes. E a realidade da vida, cruel, muito cruel, nos mostrava outras coisas. Exemplo: desaparecia Noruega, Jundiá aos pedaços, só canavial resistia. Resistia o verde das águas que Deus nos deu como suprema consolação. Desses colégios e escolas dos engenhos não mais partiriam para Paris ou para a Europa muitos mocinhos como Mario Pedrosa, Manuel Bandeira (este por motivo de doença), Heitor Maia e tantos outros como André Dias, Manuel Dias e sim para o Rio de Janeiro. A coincidência foi grande. Outra paisagem social surgia: a usina de açúcar. O homem do eito desaparecera, e com ele toda a vida dos engenhos. (DIAS, 2011, p. 47) 
Figura 2: O pintor Cícero Dias em seu ateliê.

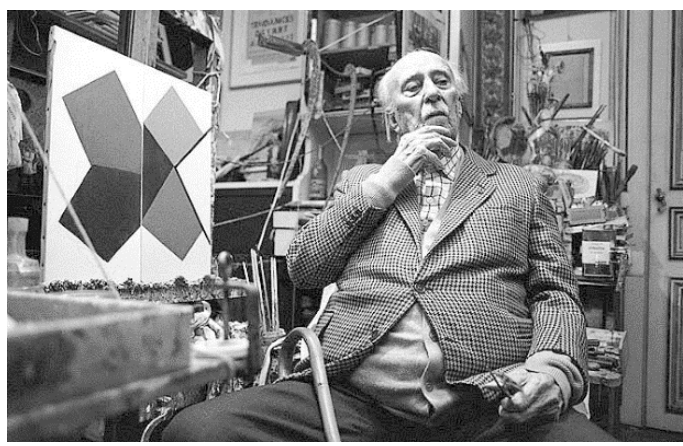

Fonte: Página do Gravura Contemporânea. ${ }^{3}$

Cícero Dias se tornou um dos maiores artistas brasileiros com vocação de vanguarda como Mario Pedrosa, o maior crítico brasileiro. Os dois da cepa pernambucana e filhos dos engenhos de Pernambuco. Enquanto Cícero Dias narra a decadência das casas de engenho, surge em São Paulo, a partir de 1906, o Engenho Central pela visão de Francisco Schmidt. Pouco tempo depois, Pernambuco deixará de ser a maior região produtora de cana-de-açúcar do Brasil. Do nordeste brasileiro para o nordeste do estado de São Paulo, se estende o eixo invisível de novos canaviais plantados para a produção do açúcar entre plenos cafezais. A vigorosa paisagem cultural pernambucana encontra, pelo fluxo econômico, a paisagem cultural da economia do Café. Do declínio dos engenhos de Pernambuco e da sua tradição secular nasce a nova força da cana-de-açúcar no Brasil sobre a terra roxa. Décadas de câmbio na lavoura suprimem cafezais e silenciam a paisagem cultural do café, criando uma nova paisagem e novos valores que mais tarde serão refletidos na nova cultura que surge desse silenciamento não proposital.

O que torna os homens pioneiros é o seu olhar sobre a paisagem. Neste ponto, existe uma semelhança entre a Coluna Infinita de Brancusi e a chaminé do Engenho Central. Uma chaminé, no entanto, chama a atenção por ser um elemento que dispersa os vapores e lembra sempre a Revolução Industrial, a força de trabalho de milhares de homens e mulheres que naquela localização comprometem toda a sua energia em nome da vida. Simboliza o avanço da produção industrial e estabelece eixos de crescimento da urbanização, criadas em torno das cidades e metrópoles modernas. No campo, as chaminés se verticalizam de maneira monumental. Diferente da obstinação de um único artista, são milhares de seres humanos guiados pelo estado de arte e não pela arte, no caso do engenho, a moverem toneladas de cana e milhares de sacas de açúcar pelo mundo, fazendo a fortuna de um pouco mais do que uma dezena de donos de engenho. A história social, no entanto, não os equivale. A riqueza distinta entre minoria e maiorias não é necessariamente equilibrada e universal.

Disponível em: https://3.bp.blogspot.com/-yPKx9oQSsdc/U9SnWFf3uhI/AAAAAAAACsw/kmWcKldODi8/ s1600/cicero_dias_galeria_de_gravura.jpg Acesso em: 11 maio 2020. 
Figura 3: Chaminé do Engenho Central.

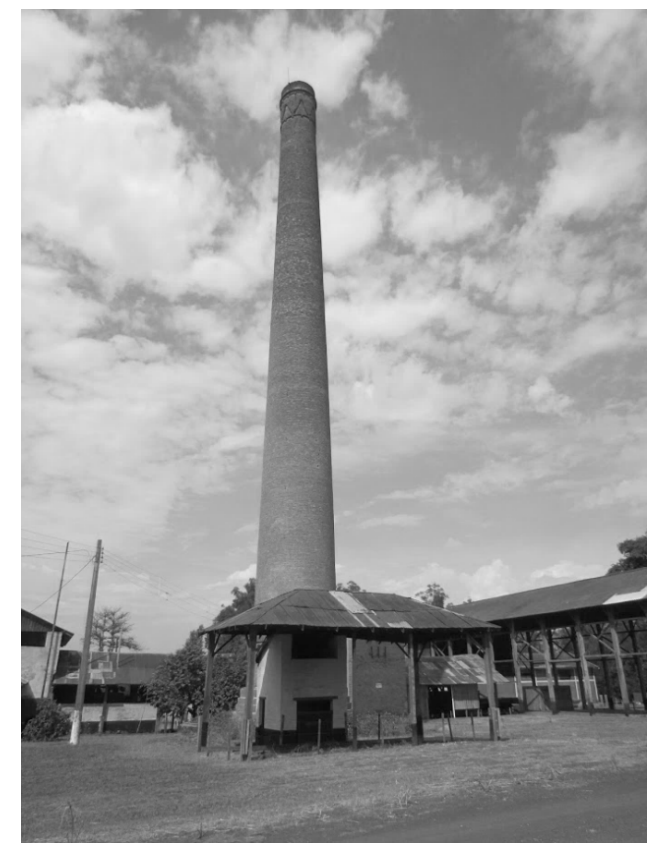

Fonte: Acervo do Museu da Cana.

A paisagem, que é local, se amplia. Eras de engenharia para moer a cana e processar o açúcar desde a sua origem. Mais uma vez, a arte e a vida se permeiam na sobrevivência humana. Milhares produzem a cana, milhões ingerem açúcar made in Brazil ao redor do mundo. O grão de sacarose é esculpido. O açúcar é esculpido pelo processo industrial da alimentação e esculpe os corpos humanos pela via da cultura alimentar. Como na pintura de Franz Post em que o gesto retrata o engenho, luz, pigmentos e imagem metabolizam o lugar que produz o alimento indispensável ao planeta, química e física estruturam a pintura e o açúcar. Menos mítico que o café, o açúcar traça a vida entre os corpos de modo invisível. Ele complementa a alimentação, a imaginação e o gosto do paladar diverso dos povos da terra. Alimento básico, o sal doce já era manejado pela perícia de engenho e mercado dos italianos no Século XV. Século do Descobrimento. Porém, é Portugal que domina o mercado do açúcar nesse período e são os pernambucanos, entre os homens mais ricos do mundo, que o farão até a década de 1930. Mistérios à parte, a Itália, coadjuvante do século XV, dominará a cena econômica quinto século do Brasil. E consigo, desde o Engenho dos Erasmos ao Engenho Central, o Porto de Santos será a porta de entrada da história sendo revertida cinco séculos depois, no Brasil, onde a Veneza mercante dos mercadores do açúcar daria lugar aos italianos que seriam por fim os donos dos Engenhos firmados na paisagem paulista. 


\section{Paisagem infinita}

[...] Quando se visita um país que não se conhece, não devemos fazê-lo com a passividade de meros espectadores. A paisagem não deve roçar displicentemente pelos nossos olhos. Nossos olhos e um pouco da nossa alma é que devem penetrar a paisagem para adivinhar-lhe toda a beleza oculta. Devemos reintegrar o nosso eu na alma do povo visitado, saborear-lhe a linguagem e os costumes, absorver-lhe a resultante psicológica, relacionar o homem com o ambiente; gravar o colorido vital da massa coletiva e conversar com o "Genius-loci". Todas as coisas e seres têm vibrações e sentimentos de beleza, necessitamos de alma sensível para os compreender. Anexo vai um artigo-paradigma de quem sabe viajar com inteligência. (FURLAN JÚNIOR, 1947.) ${ }^{4}$

O Engenho Central de Sertãozinho é nascido para as relações da museologia social, pois não é somente no patrimônio das máquinas que está a sua riqueza. Fundado na década de 1906 por duas famílias centrais da história do café, cambia para a produção do açúcar pelas mãos de Francisco Schmidt. Na paisagem cafeeira paulista, surge a ponta da tecnologia mais sofisticada da época. Sem economizar esforços, Schmidt inicia para São Paulo o que seria uma das economias mais profícuas por décadas em sucessão, trocando de mãos a propriedade do Engenho Central com a família Biagi que o fez chegar ainda produtivo, na década de 80, limiar do Proálcool. Histórias de gente vinda do exterior e do interior do Brasil. De diversos estados brasileiros e da Itália, desde Castelnuovo de Garfagnana, famílias trabalham em canaviais que expandem continuamente a paisagem da cana, devastando as terras, a história e a memória da sociedade cafeeira paulista. Se o café embalou a vida em exemplos da arte que vêm desde a Cantata do Café de Johann Sebastian Bach até o oratório cênico de Mario de Andrade, a paisagem canavieira irá silenciar a paisagem cultural erigida pelo período do café. Café que financiou a invenção da aviação, gerou inteligência cardeal e diametral no país, financiou a Semana de 22 e representou os ideais de uma elite brasileira que trouxe o Brasil para a modernidade. Povoando a imaginação de gerações. Bem diferente da cultura do Café, a sociedade da cana minimiza aspectos da cultura artística e, ao mesmo tempo implanta o vazio cultural sobre as cidades da terra roxa. O legado da Semana de XX cresce para dentro do Rio e de São Paulo. E uma vez decaído o ciclo do Café, o ciclo da Cana paulista irá criar o apogeu econômico, social e tecnológico nunca antes visto da economia brasileira. Se por um lado os engenhos de Pernambuco dependiam da tecnologia europeia, em São Paulo irá se promover a emancipação tecnológica dos engenhos brasileiros. A mudança de mentalidade, finalmente, dizendo a

\footnotetext{
4 Dr. Antônio Furlan Junior, médico da comunidade de Sertãozinho. FURLAN JÚNIOR, Antônio. [Correspondência]. Destinatário: Marina Furlan, 1947.
} 
que veio, mudará a economia da cana no Brasil, tornando o estado de São Paulo líder das áreas mais produtivas da cana-de-açúcar quando Maurílio Biagi resolve criar a Zanini metalúrgica para atender a demanda dos Engenhos da região de Sertãozinho.

E do mesmo modo como a Semana de 22 se opôs à Monarquia e seu legado intelectual e artístico, a Semana de 22 será demolida pelo Movimento de Arte Moderna instaurado no Brasil, a partir das Bienais, momento em que a sociedade canavieira encontraria seus pares depois de ter lançado seus filhos para o mundo. Se por um lado o Brasil é altamente dependente na indústria automobilística e mantendo-se como fornecedor de matéria prima, a cana brasileira será exemplo de autonomia, assim como a nova fase da arte brasileira. E da percepção dos fenômenos estéticos da sociedade moderna que ficarão muito além da arte e das linguagens de arte. A Paulicéia desvairada, o Manifesto Antropofágico e o manifesto Pau-brasil ficarão definitivamente no passado. São Paulo vai erigir o Movimento de Arte Concreta.

Fica definitivamente alterada a noção de arte e patrimônios culturais no Brasil. A arte não será mais referente ao indivíduo como na obra de Brancusi. Passará cada dia mais a valer esteticamente para os fenômenos coletivos da sociedade e é neste sentido que o Engenho e a Escultura voltam a se comunicar: nos centros urbanos, a força da tecnologia, do urbanismo, da aviação, das comunicações da arte passa a validar a beleza da obra de arte e do voo de um avião da mesma maneira. A percepção muda silenciosamente da contemplação para a interação. A técnica ganhará, na percepção inerente das pessoas comuns, o status da arte enquanto fenômeno estético, além dos visionários Schimdt e Maurilio Biagi, a pontauense Judith Lauand.

Figura 4: Judith Lauand, representante do concretismo brasileiro.

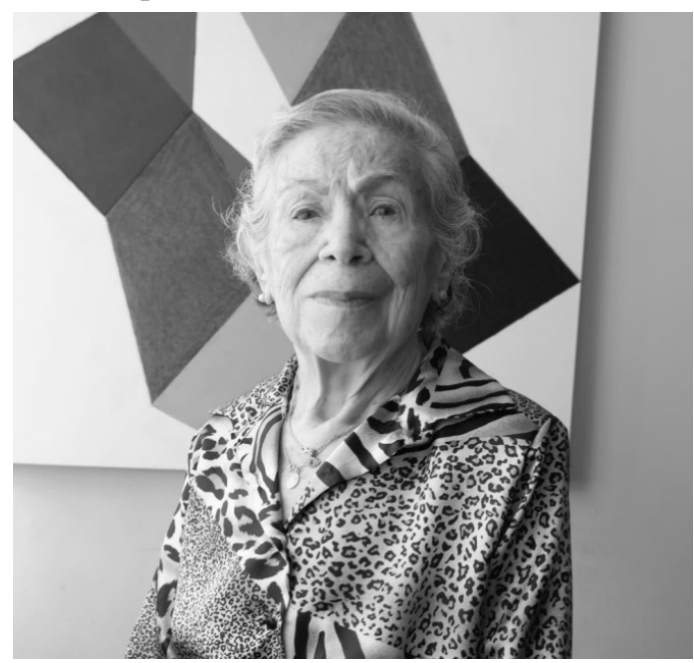

Fonte: Página da Galeria de Arte Trópica. ${ }^{5}$

5 Disponível em : https://galeriatropica.com.br/wp-content/uploads/2016/01/foto-perfil-crop-1.jpg Acesso em 11 maio 2020. 
E é justamente na arte de Judith Lauand, a dama do concretismo brasileiro, que vamos encontrar alusão ao que havia pronunciado o Flávio de Carvalho (1947), no seu extraordinário artigo, "o silêncio da grande altitude", justamente, quando ele se refere ao silêncio dos altiplanos. Tal invocação da palavra evidentemente recorda não apenas altiplanos da paisagem dos Canaviais em Sertãozinho, como os planos delineados sem desejo na geometria concreta criada por Judith Lauand. Ela que pode ser, como artista, considerada a mais nobre filha da transição entre o ápice da cultura do café, que teve como ponto culminante a Semana de 22 e a grande pausa gerada a partir de então pela transformação da paisagem de cafezais a canaviais que, com a mesma força plana, persistente e constante de uma infinidade de verdes e de trabalhos humanos de extrema lavra, lavra esta que causou a interrupção de uma realidade cultural transformando-a em um silêncio sociológico posterior à cultura do café e que posteriormente, na década de 50, responde à realidade e à arte brasileira com um dos mais originais e, ao mesmo tempo, universais movimentos da história da arte brasileira.

A arte concreta criada pelo grupo ruptura, da qual participa Judith Lauand como a única mulher integrante, causa uma verdadeira revolução na cena da arte brasileira. Vinda da informatização, da necessidade da simplificação da vida cotidiana nas grandes cidades, a estética de simplificação dos elementos da pintura moderna ganha no Brasil a tão sonhada força em sucessivas gerações para ocupar o cenário da arte internacional com artistas de grandeza e originalidade, conscientes do papel que a arte brasileira teria entre os movimentos da arte internacional. E é justamente desta força da Arte Moderna brasileira que nasce o paralelo que agora deve ser percebido com a mentalidade de um pioneiro como Maurílio Biagi. Um dos desafios da modernidade era justamente a autonomia.

Figura 5: Instalações da Zanini S.A, fundada por Maurílio Biagi.

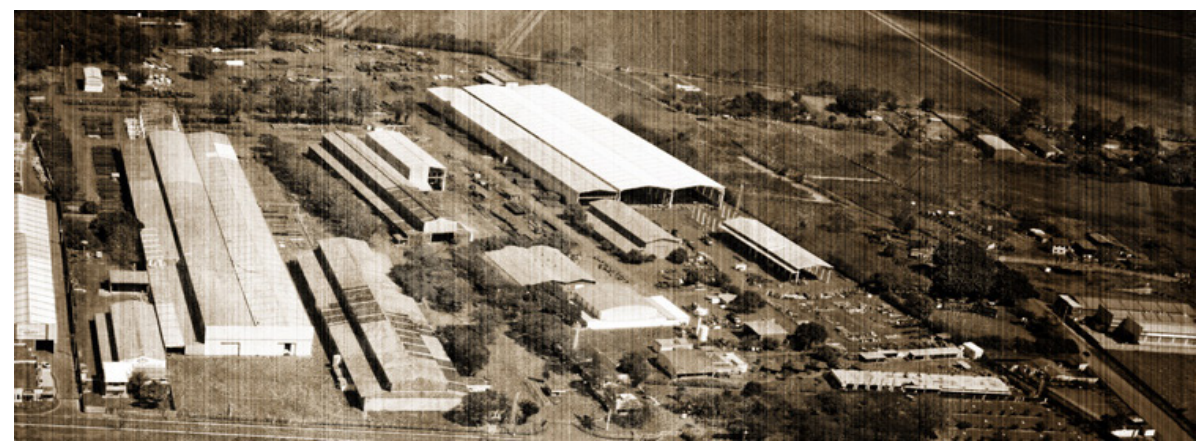

Fonte: Acervo do Museu da Cana.

E esta autonomia buscada pelos artistas foi a mesma buscada por Maurílio Biagi quando ele toma a decisão de fundar a Zanini, com intuito de criar tecnologia local para os engenhos de açúcar, rompendo com a dependência da tecnologia dos países de fora. Esta modernidade ainda não foi alcançada pelo Brasil em 2019. Esta 
modernidade foi interrompida. Porém, o exemplo do entrelaçamento entre a arte e o pioneirismo econômico neste caso se amplia. Outro exemplo da escultura para reflexão sobre a importância do Museu da Cana vem dos pares de Judith Lauand. O primeiro é Luis Sacilotto, considerado pelo contemporâneo Waldemar Cordeiro como a viga-mestra do concretismo brasileiro. Sacilotto, até hoje, mesmo após a sua morte, não teve um conjunto edificado das suas esculturas em metal, pois faltava a ele tecnologia suficiente para cortar e dobrar metal em grandes dimensões.

No entanto, não faltou a Luis Sacilotto o mesmo aspecto visionário que compõem a trajetória dos Biagi. Aqui uma pausa para aspectos da museologia social. Note-se que ao ser questionado pelo neto Luiz Biagi sobre como havia feito fortuna, seu avô, Pedro Biagi, responde-lhe o seguinte: "a pobreza tem uma história muito curta e feia. Eu te conto tudo em três frases: a pobreza é bruta, cheia de sacrifícios e muito, ma molto lavoro. E basta!" (BIAGI, P., 2015).

O que devemos considerar é que não apenas Pedro Biagi, como Volpi, Sacilotto, muitos dos membros da família Matarazzo, enfrentaram a mesma poveritá. E mesmo assim, todos eles se tornaram pioneiros. Ficamos com este trecho para refletir sobre o que é a importância da museologia social. Na própria história da criação do Museu da Cana encontramos nos arquivos da Zanini registros da viagem de Cristina Prata na qual está inserida menção a outras personalidades brasileiras, também pioneiras, porém, egressas da cultura canavieira de Pernambuco, entre elas, o fundamental designer e pensador brasileiro, pioneiro da conceituação e da terminologia de bens culturais no Brasil, Aloísio Magalhães. Na década de 70, já imbuídos de transformar o Engenho Central em museu, tal como sentiu Maurílio Biagi, Luiz Biagi e Cristina Prata, encontram no Recife não só com Aloísio Magalhães, como também Burle Marx, Acácio e Janete Borsoi, Clarival do Prado Valadares e, entre outros, havia sugestão de que se entrevistasse Cícero Dias e, surpreendentemente, como o primeiro nome da lista dos presentes na reunião, também participante do grupo ruptura, artista concreto e pioneiro do design brasileiro Alexandre Wollner. Esta reunião teria sido realizada no dia 11 de novembro de 1974.

Pode parecer uma realidade muito abstrata e intangível, mas verdade é que, desde a noção que Maurílio Biagi teve de conservar o Engenho Central para que dele nascesse um museu, a história desta criação cruzou os caminhos dos maiores pioneiros modernos brasileiros em matéria de arte, cultura, design e bens culturais. E, aquilo que poderíamos tratar rudimentarmente como um ato visionário de Francisco Schmidt ao implantar o Engenho Central no Nordeste de São Paulo seria uma simples resposta ao declínio da economia do café ou uma simples transição da produção de cana-de-açúcar de seu eixo hegemônico secular de Pernambuco para São Paulo tornou-se, no tempo, e na verdade entre gerações, um polo predestinado a inaugurar a nova economia cultural brasileira. Aloísio Magalhães foi tão profundo na conceituação da cultura que cunhou para os brasileiros e da nação brasileira para o mundo o conceito de bens culturais. Maurílio Biagi não só lutou pela emancipação tecnológica que acabou transformando o solo paulista no mais 
produtivo solo de cana-de-açúcar do país como teve a sensibilidade de, ao olhar para o moinho projetado por Schmidt, perceber que ali naquelas engrenagens que iluminaram a mentalidade universal de uma então menina de Sertãozinho, chamada Marina Furlan, tinha um potencial de transformar a visão de uma era tecnológica secular em um museu para gerações futuras. Ocorre que, justamente este Museu, está fadado igualmente ao pioneirismo. Permitam-me aqui um pequeno ato em primeira pessoa: quero registrar que desde que pisei no Engenho Central senti a ligação desta terra à meridianos bem maiores do que o ponto em que o Engenho se georreferencia. Aqui senti vivamente a necessidade de trazer ao trabalho proposto trechos da autobiografia de Cícero Dias e a benção a outro filho dos engenhos pernambucanos, maior crítico de arte brasileira, Mário Pedrosa; este que foi não só o defensor da Arte Moderna como aquele que se envolveu na vida política brasileira a ponto de transformar a arte amplamente em atividade social.

Uma das afirmações mais importantes de Mário Pedrosa é de que a arte é um direito universal do homem seja ele equilibrado ou desequilibrado, Papua ou cafuzo, letrado ou iletrado. Pioneiros são pioneiros. Dessa forma, Maurílio Biagi ao fundar a Zanini criou o ponto de mutação, a perna da emancipação tecnológica que possibilitou a emancipação econômica da cana-de-açúcar a ponto de que participamos do engenho de açúcar até chegar no Proálcool e na produção do etanol. Tecnologia também é direito da humanidade. E nas chaminés que hoje não vertem mais fumaça, pois até mesmo a fumaça é transformada em energia. Energia que, embora venha de uma cultura que agride o solo, é altamente significativa em proteger a atmosfera da emissão de carbono.

Deste lugar, a arte, o pioneirismo econômico e a vocação maior de homens que não só mudam a realidade de seu tempo, mas que compreendem a importância daquilo que é cultura como bem essencial da humanidade, tangenciamos os desafios sociais e ambientais. Lembro aqui que Alexandre Wollner, um artista cuja pintura tinha extrema importância deixou de pintar porque ambicionava fazer arte para milhões e não para centenas de pessoas. Aqui a ambição criativa de Wollner encontra a capacidade visionária e pregressa de Santos Dumont, Francisco Schmidt e Maurílio Biagi. E os desafios continuam, pois, colocar a arte em ampla escala na vida humana ainda é um desafio. A museologia social será uma das maiores ferramentas para auxiliar nas tendências a tarefa. E a história do Museu da Cana entrelaça pioneiros. Esta é uma verdade da qual todos que vislumbram este museu e a importância que ele tem para o desenvolvimento local e nacional não poderão se furtar. E a história mesmo em tempos pós-históricos deve ser ambicionada e construída de modo verídico. E o modo verídico da sociedade atual é aquele que equivale à comunidade como a grande guardiã da cultura, como sentiram Mário de Andrade e Aloísio Magalhães. É a nossa vocação emancipar não apenas a tecnologia, mas a arte, a ciência, a educação, a filosofia e a noção de economia cultural da qual não poderão se furtar as bases de criação institucional deste museu. 
O Museu da Cana, diga-se bem, é por excelência um fato da museologia social brasileira se levado a cabo. Pois, não é somente a história de Maurílio Biagi o cerne deste museu. Vamos deixar a metáfora entre as chaminés e a Coluna Infinita de Constantin Brancusi para trás e pensar que o silêncio da grande altitude está no desafio da paisagem infinita, que trouxe para os trópicos populações que carregavam os Alpes gelados da Itália dentro de si, e que o confrontamento das paisagens interiores e externas dos povos que habitavam o entorno do Museu da Cana e estes canaviais é múltiplo. O multiétnico e desafiador, como previu Euclides da Cunha em Os Sertões, torna-se multicultural como bem descreve Mario de Andrade em Café (o romance). Para este museu, se visto na expansão do tempo, contam não apenas os aspectos visionários de Maurílio Biagi como a capacidade de seus herdeiros de preservar a sua intenção originária de transformar o Engenho Central em um museu. Conta, além disso, a persistência de homens comuns que habitaram e mulheres como dona Edilah, dona Nair e dona Vanda e tantas outras vidas anônimas dedicadas ao trabalho na usina de açúcar. Este lugar não é um lugar comum. É um lugar cuja energia e o senso de preservação por alguma razão se deu entre classes sociais, povos de culturas diferentes e gente com e sem os dons do pioneirismo. Não é muito, já que a ciência contemporânea se desafia a crer em Deus, projetar ao espectro da museologia social que aqui se aplica que do ponto de vista sociológico esta noção de Cultura presente no espaço do Engenho Central tenha como força motriz e criadora a força do amor. Amor não só com afeto, mas também com a consciência do valor das vidas aqui vividas.

Diz a lógica que, numa região rica em todos os sentidos, o cruzamento de pioneiros pernambucanos, ítalo-brasileiros, mineiros, brancos, caboclos, gente da terra, gente pobre que aqui chegou e cumpriu seus destinos e nem todos com a grande sorte de enriquecer, a força harmônica entre as classes sociais certamente não é baseada em mais-valia e sim no amor que fornece uma certa noção de desobediência civil, pois as pessoas que contêm o amor dentro de si são capazes de perceber e persistir pelos valores humanos com uma força incomum e quase sobrenatural e, quando não sobrenatural, baseada na profunda religiosidade. No caso da paisagem religiosa do Museu da Cana, uma religião e religiosidade sincretistas, onde a força de um João Baiano equivale a força do catolicismo aqui presente em festas consagradas a São Sebastião, Santo Antônio, São Gonçalo, São Pedro e Santa Luzia. Riqueza esta que na contemporaneidade só pode ser sintetizada por artistas como Jorge Mautner. Artistas que superaram o desejo antropofágico, o expressionismo moderno de Anita Malfatti e Flávio de Carvalho e a planificação Concreta e Neoconcreta e tropicalista. De canções como Maracatu Atômico, inspirada nos maracatus de Solano Trindade à Ruth Rainha Cigana, canção numa história de amor, se encontra a tradução da realidade multicultural, multiétnica e sincretista e afro-religiosa, essencialmente baseada no catolicismo que mantém as festas populares presentes no Engenho Central e que hoje são parte do patrimônio imaterial do Museu da Cana. Diz Mautner na sua canção: 
O fim sem fim da doçura do amor

Supera tudo que seja lá o que for

Até mesmo o terror da dor que emana

Da fúria de um açoite

Ó Ruth, rainha cigana, estrela da noite

Somos casados há 50 anos

Deus nos deu a maravilha

Rainha da graça divina

Que vinha com o nascimento da Amora nossa filha

e o nascimento da Júlia, nossa netinha

Nossos amores, nosso axé, por isso vou cantando

Agradecendo e rezando pra Jesus de Nazaré

Ao som dos tambores do candomblé

Ao som dos tambores do candomblé

Ao som dos tambores do candomblé

Ao som dos tambores do candomblé

No evangelho de São João uma voz em júbilo anuncia: -

Uma criança nasceu entre nós!

Jesus de Nazaré também disse: -

Mais vale aquela ovelha que se separou do rebanho

E depois voltou para ele

Do que aquela que sempre pertenceu ao rebanho

E como disse São Paulo

- De que adiantaria se eu soubesse

todas as línguas e ciências e não tivesse caridade?

E também

- mesmo quando não houver mais nem fé, nem esperança

o amor continuará a resplandecer no universo

O fim sem fim da doçura do amor (...)

Ao som dos tambores do candomblé ${ }^{6}$

Célebre, Jorge Mautner, na fase atual da sua vida fala de amor. Do tipo de amor profundo do qual nenhum de nós, seres humanos, nos livramos de refletir em algum momento da vida. Fortes como as paisagens infinitas são os homens e mulheres que nem sempre artistas visionários ou pioneiros se comunicam entre si pelo estado de arte. E o que é o estado de arte senão o profundo estado de atenção

\footnotetext{
6 MAUTNER. Ruth Rainha Cigana, 2019.
} 
para o qual a nossa concentração nos leva quando atingimos estados conscientes da nossa existência?

Nesse sentido, o Museu da Cana cruza fronteiras. Fronteiras de gente que aqui foi visionária, vislumbrou, viveu, trabalhou, amou e, através dessa força, transferiu suas próprias paisagens internas para as paisagens internas das gerações que sucederam. A missão da paisagem infinita é esta: superar confrontos, contradições, diferenças, e justamente alcançar as semelhanças que unem os seres humanos para transformar a humanidade.

Do coração que é terra onde ninguém anda, surgem as universalidades percebidas na canção na qual Mautner homenageia o amor. Assim, há uma paisagem infinita também que expande as terras do coração, pois, embora ninguém ande nelas, é nos nossos corações que sentimos a presença do outro e, como bem lembra Dona Nair, "o amor é uma força que brota do fundo do coração". ${ }^{7}$

E das profundezas da terra, a força de imigrantes e migrantes que migraram apenas com a força que brota dos corações para cruzar oceanos e refundar o Brasil. Muito ilustres e não só anônimos, migrantes surgem na visagem do filho célebre da imigração italiana no Brasil, um dos maiores pintores modernos. No quadro Retirantes, da autoria de Candido Portinari, talvez, não seja agradável apreciar a vida morta dos retirantes. Por outro lado, não se pode aceitar que aquela paisagem dos retirantes continue congelada na realidade social brasileira. É, portanto, um grande mérito de relações tecidas sobre as terras do Engenho Central ter havido um equilíbrio que da pobreza trouxe a superação da pobreza, que, para alguns, foi a origem da riqueza material e para outros foi a sorte de encontrar o respeito pelo trabalho, pela fé, pelo ambiente onde foram criados os filhos nem tão nobres da cultura dos canaviais. Mas foram eles, os filhos anônimos dos canaviais junto aos seus filhos notórios, que trouxeram o horizonte cultural da vida até o ponto em que um engenho, ao invés de ser demolido, pudesse se tornar o início daquele que poderá ser um museu inovador, humanista, corajoso no sentido de edificar a cultura da liberdade como ponto de partida para o Brasil, que merece usufruir do pioneirismo de tantos pioneiros que foram consultados na origem do projeto desse museu, na década de 70 , e que persistem na memória daqueles que percebem a vida como estado essencial da arte e a arte como estado essencial da vida. Sendo assim, não é demais sonhar que obras, imagens, acervos materiais e imateriais sejam projetados do Engenho Central para o mundo buscando a superação das contradições ambientais, sociais, culturais e econômicas que fizeram parte do passado dos canaviais e fazem parte do presente dos museus brasileiros.

Ninguém quer mais encontrar as cenas vivas de retirantes congeladas na atual realidade brasileira dos dias de hoje. Aqui, o amor se transcende para a consciência.

\footnotetext{
Nair é antiga moradora da colônia do Engenho Central. Conversa informal em visita /pesquisa no Museu da Cana em agosto de 2019.
} 
Figura 6: Família Biagi.

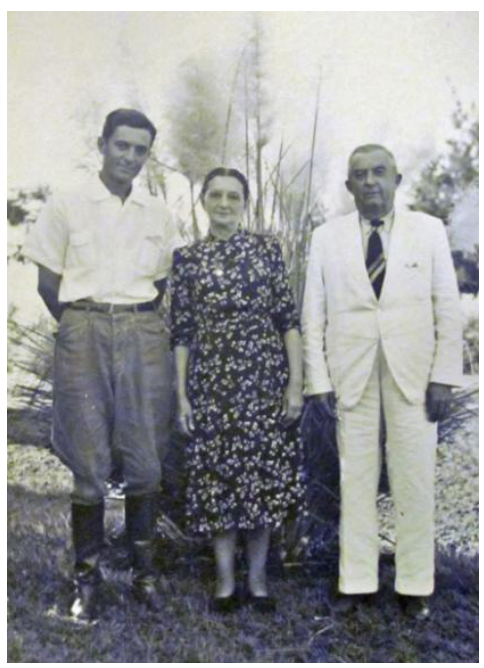

Fonte: Página do 100 Nonni. ${ }^{8}$

Um pêndulo desigual de memória entre Maurílio Biagi, que transita na instalação de um engenho de bangue, e um senhor Otacílio, que guardou na sua solidão, por décadas, a porta de entrada de um Engenho Central, é hoje museu que pode guardar e difundir os bens, as relações, a materialidade e a sensibilidade tangível de tantas percepções diferentes que trouxeram o Brasil secular ao Brasil presente. Da canção de Jorge Mautner, faço vivas as palavras de Luiz Biagi, as mesmas que unem a todos nós em ideais comuns de criação: não apenas o Engenho Central foi um viveiro de empresários mas, além de ele ter sido no passado viveiro de empresários, continuará vivo no presente, sendo o Museu da cana um viveiro de novos empresários da economia cultural, em que artistas e designers sociais de uma nova realidade social incluam bens culturais e criativos no panorama desta diversidade. Ele mesmo ressalta a importância de

homenagear todas as imigrações importantes que vieram para o Brasil, através de uma música geografia que possa contar a história de forma visual, voltada para crianças e explicar a etnia e a cultura que nós somos, que o Brasil é e o estado de São Paulo é, contados detalhes, em números, algo bem feito, explicar de onde vieram do Japão, Itália, Alemanha, quantos vieram para as regiões, para onde foram, o biotipo das pessoas, os cruzamentos, mostrar a cara de quem com quem [...] (BIAGI, L., 2003).

\footnotetext{
8 Disponível em : https://lh3.googleusercontent.com/proxy/VyLZt8NuLOI8yNoSo9AGh2p8EcKuKvXEyU34q0X 1sTs19d1uWOfB0Tb5xnfLIfoCfVP28aQLarjfpdC-AgvS8KsIzU4xAvvcG6s7_8zBLxGaC419scApoMhu Acesso em 11 maio 2020.
} 
Entre gerações passadas, presentes, futuras, se trabalhado com absoluta coragem, ainda, este museu poderá alavancar para o futuro a memória do IAA e do Próalcool, tornando-se parte fundamental do complexo museológico do estado de São Paulo. Um centro de tecnologias inclusive culturais. Um lugar onde a consciência atinge níveis de ação e racionalidade capazes de unir a coragem, o coração, a consciência e a vocação de migrar a história do presente para o futuro. E este museu é uma saga do futuro. Como a força do amor e a força de quem ama e é por esta força capaz de transformar a si e o Outro e lutar até o fim por aquilo que acredita. Capaz a ponto de tornar o amor quase uma desobediência civil. O amor que é a energia motriz da criatividade humana. A raiz das relações sociais e seu equilíbrio. De repente, o olhar que une os sentidos exemplificados entre gerações. Uma vez mais, a força humana se une de modo quântico para multiplicar potenciais infinitos. E nasce uma primeira leitura da predestinação coletiva de um museu que pertence ao futuro e não ao passado.

Figura 7: Formas pão de açúcar e engrenagem de Engenho de Bangue adquiridas em Pernambuco, hoje no Museu da Cana.

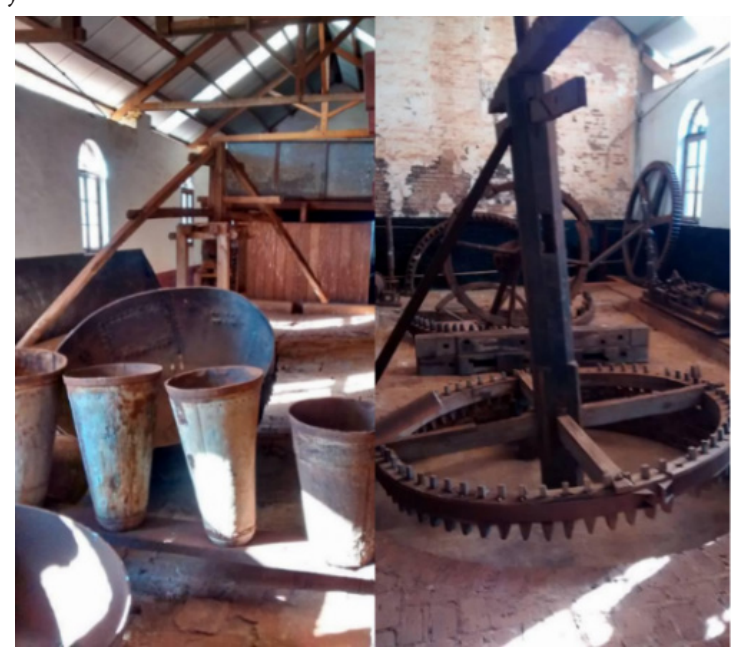

Fonte: Acervo do Museu da Cana.

Misteriosa correspondente diminutiva da palavra Sertão, Sertãozinho, localizada no Nordeste de São Paulo, torna-se um ponto de ligação com a cultura de Pernambuco. Por ser um dos maiores bens culturais do Estado, o Engenho Central, lugar de origem do Museu da Cana, traça o destino, na década de 1970, olhando o passado para premonitoriamente caminhar para o futuro. Nordeste paulista ligado a Pernambuco por um eixo imaginário no espaço e no tempo, torna-se uma das ligações culturais mais importantes da contemporaneidade, pelo viés de Aloísio Magalhães, que desenhou o Museu do Açúcar, em 1965, lugar onde Cristina Duarte Prata foi buscar o engenho de bangue, que integra hoje o conjunto do Engenho Central. 
No ano de 1974, Cristina Duarte Prata, então coordenadora do Museu de Sertãozinho, financiada pela Zanini, inicia uma série de viagens na região dos Engenhos dos Estados do Norte e Nordeste. Precisamente, no dia 3 de março de 1975, em relatório semanal, após narrar um encontro com o delegado do IAA, e com o sociólogo Gilberto Freyre, viajando com Zé Santeiro pelo Estado da Paraíba, em diversos encontros em busca de peças para a formação do museu idealizado inicialmente, ela descreve a pessoa de Aloísio Magalhães em carta a Luiz Biagi, no seguinte contexto:

Quem me deu uma grande força nas transações foi o Aloísio Magalhães que veio passar o mês de fevereiro aqui. Ele me sugeriu ainda que procurasse entrevistar Ariano Suassuna, Capiba e Cícero Dias. Aloísio se interessou muito pelo museu e é super por dentro de várias transações (tem escritório de Programação visual, foi ele que desenhou as cédulas de dinheiro atualmente e está se empenhando em criar em Brasília "centro de referência cultural", seria um centro que reuniria todos os dados e informações sobre a cultura do Brasil. É um cara dinâmico, entusiasmado, cheio dos contatos. Fiquei de mandar para ele uma cópia do projeto do Dr. Clarival. Ficou bastante interessado no projeto do museu e queria até falar com você. Dei a ele os telefones do escritório (PRATA, 1975).

Hoje, o Engenho Central de Sertãozinho tornou-se um lugar de preservação da história, como anteviu Maurílio Biagi, filho do imigrante italiano Pedro Biagi. E mais que mudar a geografia econômica do açúcar e da cana, o museu intersecciona a história à memória italiana no Brasil de um modo completamente inusitado que liga o fluxo imigratório ao trajeto de Aloísio Magalhães, talvez o mais alto representante da cultura pernambucana. Do ponto de vista da história do museu, existe um elo fundamental entre Brasil e Itália que amplia a concepção do museu e pode ser entendido pela condição de vida dos italianos, da maneira como nos descreve Luiz Biagi (2003) nos trechos da sua memória sobre a criação do museu: "Eu sempre quis preservar o Engenho Central, por sua importância histórica. A primeira Safra, foi em 1906, na substituição do café. A preservação foi fácil, meu pai (Maurílio Biagi) determinou que preservássemos o local”. Referindo-se à colônia do Engenho, Luiz Biagi cita a presença de Attilio Balbo no período em que o patriarca Geremia Lunardelli trabalhou com Schmidt. E continua, comentando que:

Na época da Zanini (1970) pensei em outro museu, da história da indústria do açúcar, mas moderno, em outro local, que seria em Sertãozinho. Tive contato sobre ideia com o arquiteto Borsoi, de Recife, Pernambuco, mas não prosperou. Estive com Oscar Niemeyer, no Rio, porque tive vontade de fazer o Museu do 
Imigrante. Esse seria na Rodovia Anhanguera, para homenagear todas as imigrações importantes que vieram para o Brasil, contar essa história de forma visual, voltada para as crianças e explicar a raça e a cultura que nós somos, que o Brasil é e o Estado de São Paulo é, contar nos detalhes, em números, algo bem feito, explicar de onde vieram do Japão, Itália, Alemanha, Quantos vieram, para as regiões, para onde foram, o biotipo das pessoas, os cruzamentos, mostrar a cara de quem com quem... Seria um museu muito interativo, como o da Língua Portuguesa, mas com caras, informações de pessoas, de genealogia. Não deu certo, Niemeyer não levou adiante, não apresentou o trabalho. A ideia do museu no Engenho Central estava totalmente desativada, mas em 2006, eu reativei o projeto no Ministério da Cultura. A ideia de fazer, olhando o meu avô, meu pai, e me olhando, a vontade de fazer alguma coisa, não de ser dono, de ter, ou de enriquecer, mas fazer, mesmo que passasse depois para outras mãos. Enfim, todas as empresas constituídas são operativas hoje, no horizonte de 100 anos, todas estão funcionando, nenhuma fechou. Talvez o mérito maior da família tenha sido a vontade de empreender, que vem do sangue italiano e da extrema pobreza de que eles vieram da Itália. (BIAGI, L., 2015)

Figura 8: Aloisio Magalhães.

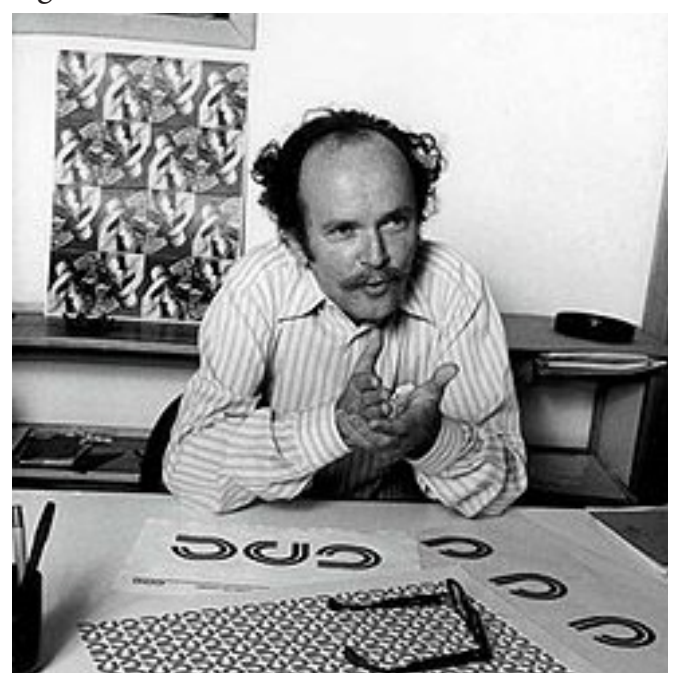

Fonte: Página da Wikipedia9.

9 Disponível em: https://upload.wikimedia.org/wikipedia/pt/5/5b/Aloisio-em-seu-escrit\%C3\%B3rio.jpg Acesso em 11 maio 2020. 
E como uma premonição da realidade cultural brasileira esta mesma Itália de onde vieram estes italianos em extrema pobreza, de um modo quase dramático e edificante das predestinações e das leis do destino, encerra de modo súbito a vida de Aloísio Magalhães, um dos maiores artistas, designer, político-cultural e visionários da cultura brasileira, que a partir da observação da nossa sociedade e do olhar de Mário de Andrade, percebeu e cunhou de modo pioneiro o termo bens culturais. Na mesma Itália onde se passa o episódio da morte de Aloísio Magalhães, onde há hoje um Ministério de bens culturais, exemplo que o Brasil ainda não conseguiu, nem mesmo para valorizar o sentimento e a presença de espírito no olhar de homens como Maurílio Biagi, que além de uma fortuna feita pelo talento de empreender, percebeu a importância do Engenho Central de Sertãozinho como um bem cultural brasileiro.

No dia 9 de junho de 1982, Aloísio Magalhães viaja para a Europa a fim de participar de reuniões de órgãos internacionais de Cultura. Leva consigo 11 litografias em que fixou a sua visão pessoal de Olinda, imagens que o artista gráfico pretende usar no diálogo com os membros do Comitê do Patrimônio Mundial da Unesco. A viagem começa por Veneza, onde participa da reunião de ministros da cultura dos países de língua latina, como representante do Ministro da Educação e Cultura, Rubem Ludwig. Na sessão de abertura, Aloísio faz um pronunciamento - uma defesa apaixonada e vêemente das questões prementes da nossa sociedade em oposição àqueles habituados a tratar a cultura exclusivamente por sua vertente culta. Logo após sua fala, é eleito presidente do encontro. Após o almoço, na retomada dos trabalhos, não se sentiu bem e, logo após dar a palavra ao representante da França, Aloísio é internado numa clínica, onde sofre, num espaço de duas horas, duas hemorragias cerebrais. Transferido para o centro de reanimação do hospital Civil de Pádua, ali vem a falecer no dia 13 de junho, aos 55 anos completos. (MAGALHÃES; LEITE, 2017, p.522)

Trinta e um anos após a sua morte, é inaugurada a primeira etapa do Museu Nacional da Cana-de-Açúcar nas antigas instalações do Engenho Central de Sertãozinho. Um museu feito para a contemporaneidade e não para manter apenas o passado. Um museu que possui a força de ter criado sinergia entre história, memória e alcançar o sentido da museologia social como fundamento, uma vez que a simples preservação do maquinário do Engenho Central seria insuficiente para transformar o espaço em museu. Dos italianos que vieram reinventar a própria saga e a economia do açúcar, criando a continuação do fim sem fim como não sabia Cícero Dias, autor de obras que encontram a maestria de Judith Lauand com a mesma geometria que inovou 
a arte do século XX, passando por milhares de trabalhadores que sustentaram as fortunas erigidas por mais de 100 anos, até a morte regressa de um artista de vanguarda, como Aloísio Magalhães, na Itália, na mesma proporção há uma história do presente.

Aqui se cruzam os destinos dessa saga a nova era de capitais humanos e culturais, capitais intelectuais e históricos e tecnológicos que serão os únicos capitais plausíveis para que o Brasil reescreva sua economia na Era do Capital Cultural com a mesma autonomia e a coragem como que Maurílio Biagi teve para tornar São Paulo independente da tecnologia externa. Quem sabe, seguindo seu exemplo, possamos tornar Sertãozinho no epicentro de um complexo cultural tão inovador quanto foi o projeto que a Zanini representou. Não é todo museu que atrai séculos de cultura, como atraiu Pernambuco e que, em seu capital histórico, possui juntos, Maurílio Biagi, Cristina Prata, Aloísio Magalhães, Burle Marx - este, lembrando os desafios ambientais do Museu da Cana, Clarival do Prado Valadares, Alexandre Wollner, Marcelo Ferraz e, indiretamente, a memória obrigatória de Judith Lauand. Como diria Dona Edilah Lacerda, "nada é por acaso". E não sendo um simples roçar na retina, certamente, se verá a magnitude da paisagem cultural infinita e predestinada ao significado revolucionário dos bens culturais, o destino e a missão desse museu que tem absolutamente tudo para ser a grande referência do homem que é de lá e cá, não sendo mais o imigrante ou o brasileiro e sim o homem que representa a cultura do Atlântico e que possui a dimensão do açúcar produzido no Brasil e consumido, há séculos, pelo Mundo. Ou seja, o Museu da Cana tem a globalidade do açúcar como fronteira de sua cultura imaterial. Nasceu para a museologia social, os bens culturais, a preservação da memória do IAA, do Proálcool e o futuro de uma mentalidade em que o conceito de tecnologia estará ligado à biodiversidade e não confinado às redes digitais. Buscando assim o equilíbrio cultural, ambiental, espiritual, econômico e criador, como se desenhou, na origem coletiva da concepção do museu, e a exemplo da capacidade ética individual desses que são os nossos pioneiros. 


\section{Referências}

BIAGI, Luiz. [Entrevista]. 2003 e 2015. Arquivo Museu da Cana.

BIAGI, Edilah Lacerda; HASSE, Geraldo; HECK, Leila Engenho Central e Fazenda Vassoural. Pontal: Editora Elza Luli Miyasaka, 2014.

BIAGI, Luiz Lacerda. A família Biagi, os primeiros cem anos. Ribeirão Preto: Laserprint Editorial, 1988.

CARVALHO, Flávio de. O silêncio da grande altitude. O Estado de S. Paulo. São Paulo. s/p. 14 de dez. de 1947. Fundo FC/CEDAE.

DIAS, Cicero. Eu vi o mundo. São Paulo: Cosac Naify, 2011.

DORETTO, Maria Lucia. O estilo Luiz Biagi de criar negócios. Ribeirão Preto: Editora Gente, 2015.

FURLAN JÚNIOR, Antônio. [Correspondência]. Destinatário: Marina Furlan, filha de Furlan Júnior, acervo de família, 1947.

HASSE, Geraldo. Maurílio Biagi- o semeador do sertão. Sertãozinho: Editora Céu e Terra, 2003.

MAGALHÃES, Aloisio; LEITE, João de Souza (org.). Bens Culturais do Brasil: um desenho projetivo para a nação. Rio de Janeiro: Bazar do Tempo, 2017.

PRATA, Cristina Duarte [Correspondência]. Destinatário: Luiz Biagi. 3 mar. 1975. Arquivo Museu da Cana. 